JOSE CASO GONZALEZ

\title{
Rococó, Prerromanticismo y Neoclasicismo en el teatro español del siglo XVIII
}

\section{Planteamiento del problema ${ }^{(\mathrm{I})}$}

Uno de los problemas de la historia literaria del siglo XVIII español es el de periodizar adecuadamente ese largo lapso de tiempo. No se trata de buscar cómodas categorías hislóricas, que puedan incluso ser categorías estéticas o críticas, sino de ver con la mayor exactitud posible la dinámica de la historia literaria, de establecer períodos exactamente delimitados, no sólo en el tiempo, sino incluso en lo que significan en el constante moverse de los gustos lite-

T. El compromiso de publicar inmediatamente las tres conferenclas pronunciadas en la III Reunión do Lengua y Literalura española del siglo XVIII. me obliga a dejar este rabijo en la forma que inicialmente tuvo. El in dirigido a nuestros alumnos de la Facultad do Letras condicionó el texto jor ní preparado, en cuanto a la seleceión del material y en cuanto a dar fareforencia a la exposictión de mis opiniones, puesto que en definitiva el contraste de pareceres surga de ser tres los conferentiantes que iban a uratar 
rarios las fuerzas históricas que actúan sobre ellos. Esto es lo que ha pretendido la Cátedra Feijoo con esta III Reunión: delimilar, en la medida de lo posible, tres períodos, el rococó (y de antemano digo que este término, muy propio de la historia del arte, me gusta muy poco para la historia literaria), el prerromántico y el neoclásico; buscar los caracteres que distinguen a cada uno de los tres periodos, lundamenlalmente los diferenciadores, y a través de lodo esto tralar de ofrecer una imagen más exacta de la dinámica histórico-literaria de la segunda mitad del siglo XVIll.

Durante mucho liempo se llamó neoclásica a la literalura de esos años. El Neoclasicismo empezaba con la Poélica de Luzán, enlazaba casi un siglo después con el Romanticismo y se caracterizaba en especial por la adopción de una estética y una poética de origen francés. Con esto quedaban englobados bajo la misma etiqueta autores y obras muy diferenles. Hace unos cuantos lustros se empezó a hablar de Prerromanticismo, con lo que generalmente se quería significar una simple anticipación de rasgos propios del Romanticismo. Y así están más o menos las cosas en la crítica oficial: el siglo XVIII sigue siendo neoclásico, atuque algumos autores de sus últimos años se califiquen de pre-rrománticos, en tanto que son autores que anteceden al Romanlicismo pleno, y en los que aparecen rasgos que permiten relacionarlos con el movimienlo romántico.

Aparte de que esta forma de ver la historia literaria del siglo XVIII procede de no discernir los matices diferenciadores, por poner el acento sólo en los uniformadores (por ejemplo, en las reglas), creo que hay también un error de perspectiva al contemplar la dinámica histórica, por no

te los nismos problemas, y ya que en el coloquio que se seguiría a la conferencia habría ocasión, como en realiclad hubo, dis matizar y aclarar. Ifubiera preferido poder ampliar esle trabajo, para que no resultara tan csquemático; pero espero volver pronlo sobre el tema, y entonces subsanaré en la medida de lo posible los defectos que ahora tiene. He renunciado a citas bibliográficas; pero no yuedo dejar de señalar un importante trabaju cue quedó fuera de la bibliogralía consultada, porque llegó a mi conocimiento con posterioridad a la redacción de estas páginas. Me refiero al artículo de Helmut Hatzfeld titulado "Gibt es ein literarisches Rokoko in Spanien?", Ibero-romania, I (1969), págs. $59-72$. 
valorar debidamente los estilos de transición. La realidad es que los críticos desean que conceptos como Renacimiento, Barroco o Romanticismo sean aplicables sin ninguna dificultad a las obras correspondientes. Pero esto es imposible, porque apenas hay obras que respondan totalmente a um estilo puro. Lo normal de todo estilo es que nazea y se desarrolle en medio del anterior, que tenga después un periodo más o menos largo de plenitud (cuando se han asimilado ya los rasgos estilísticos anteriores y comienzan a apuntar otros que cuajarán más adelante), y que finalmente acabe diluyéndose entre estos nuevos rasgos que crecen y maduran; pero la historia no es una etapa de precedentes, más una de plenitud, más una de decadencia, seguidas de una nueva de precedentes, plenitud y decadencia. La historia es constantemente y al mismo tiempo un nacer, crecer y morir, porque en todo momento está conviviendo lo nuevo con lo viejo, lo maduro con lo que empieza o termina. Nuestro afán por ver hitos en la historia (y no digo que no existan) nos lleva al error de creer que los estilos son algo perfectamente definido y diferenciado que ocupa un tiempo delerminado, y a creer que todo gira en torno a esos hitos. Incluso se olvida demasiadas veces que plenitud de un estilo y valor absoluto de sus creaciones son dos magnitudes heterogéneas, porque un estilo en la etapa de plenitud puede no producir ninguna gran obra, y, al contrario, una gran obra puede pertenecer a una clara etapa de transición, como en la literatura española son de transición la Celes. tina y el Quijote.

Por todo esto, la periodización literaria no puedo verla más que en función de un concepto dinámico de la historia, que lleve a acolar pequeñas parcelas temporales, para permitir un mejor conocimiento de los rasgos comunitarios de ese momento, es decir, de todo el conjunto de ideas, preocupaciones, problemas, deseos, formas, tópicos, prejuicios, etc., que constituyen el ambiente literario en el que todos viven y dentro del cual surgen las obras literarias, cada una de las cuales tendrá a su vez sus características propias, como cada uno de nosotros tiene una cultura, un gusto, unas ideas, unos problenas que son exclusivamente suyos, 
aunque en lo fundamental coincidan con los de sus contem. poráneos.

\section{Los grupos generacionales de la segunda mitad del siglo XVIII}

El criterio de ordenación que parte de las generaciones parece, a pesar de los muchos problemas que plantea, y en los cuales ahora no me es posible entrar, que es el mejor para orientarse. De todas formas podemos hablar de grupos generacionales, dando a esta expresión el sentido de escritores cuya actividad literaria ocurre aproximadamente en los mismos años y se centra en problemas estéticos parecidos.

En la segunda mitad del siglo XVIII encontramos así tres grupos generacionales fundamentales: el primero to componen gentes nacidas en torno a 1735, el segundo escritores nacidos alrededor de 1750 , y el tercero los que nacen sobre 1762. Al primer grupo generacional pertenecen fray Diego González, Nicolás Fernández de Moratín, Vicente García de la Huerta, Clavijo y Fajardo, Cándido María Trigueros, Francisco Javier Lampillas, Ramón de la Cruz, Lorenzo Hervás y Panduro y Francisco Cerdá y Rico. Al segundo pertenecen Jovellanos, Pedro Montengón, José Iglesias de la Casa, Tomás de Iriarte, Félix María de Samaniego, José Cadalso, José María Vaca de Guzmán, Esteban de Arteaga, Fernández de Rojas y Antonio de Capmany. El tercero está integrado por Meléndez Valdés, Cienfuegos, Leandro Fernández de Moratín, Juan Pablo Forner, Francisco Sánchez Barbero, el Conde de Noroña, Juan Bautista de Arriaza, José Marchena y José Vargas Ponce.

A estos tres grupos fundamentales antecede otro compuesto por José Antonio Porcel y Salablanca, Pedro Rodríguez Campomanes, Andrés Marcos Burriel y Tomás Antonio Sánchez; dentro de la actividad pública de este grupo, por lo tardío de sus obras, entran también Agustín de Monliano 
y Luyando, cuyas tragedias se publican en 1750 , y el P. Isla, que edita la primera parte de su Fray Gerundio en 1758.

Este grupo generacional que antecede a los tres que nos interesan es fundamentalmente crítico, y con él comienza la Ilustración española; pero es una generación educada en el barroquismo. El grupo de Nicolás Moratín y García de la Huerta es el fundamentalmente rococó. El de Jovellanos y Cadalso es un grupo de transición; todos sus miembros nacen a la literatura en pleno Rococó, pero evolucionan después, en su mayor parte hacia el Prerromanticismo, aunque todos tienen atisbos neoclásicos, aparte de que entre ellos eslá un teórico del idealismo neclásico como Arteaga. El último grupo es a un tiempo prerromántico y neoclásico, con unos autores que, como Meléndez Valdés o Cienfuegos, se inclinan al Prerromanticismo, y otros que, como Moratín, son decididamente neoclásicos.

Todo esto significa que entre 1760 y 1775 predomina una estética de gusto rococó, que entre 1775 y 1790 hay un periodo de afirmación del Prerromanticismo, y en el que nace el Neoclasicismo, y que entre 1790 y 1810 se producen las obras más claramente prerrománticas, al mismo tiempo que las primeras neoclásicas de alguna importancia.

Deslindar en la literatura dramática estos tres momentos de la historia literaria, con la intención de aclarar los conceptos de Rococó, Prerromanticismo y Neoclasicismo, es lo que pretendo hacer a continuación. Para ello utilizaré sólo algunos ejemplos, entre los muchos que podrían alegarse, porque los límites de una conferencia no dan para más. Insistiré algo más en el teatro rococó, por ser el concepto más discutible y menos conocido. 


\section{I \\ El teatro Rococó}

\section{"La petimetra" de Nicolás Fernández de Moratín}

Una obra cierlamente secundaria desde el punto de vista arlístico, pero que al mismo tiempo me parece un buen ejemplo del Rococó dramático, es La petimetra, de Nicolás Fernández de Moratín, escrita hacia 1760, no estrenada nunca y publicada en 1762. Para centrar los problemas que me interesan nada mejor que recurrir a dos párrafos de su hijo don Leandro. Dice éste de La petimetra en la Vida de don Nicolás, escrita para preceder a la edición de 1821: "Comedia sujeta al rigor del arte, la primera original que se había escrito en España con este requisito". Y en el Prólogo que puso a sus propias comedias, y que es en realidad una historia del teatro español en el siglo XVIII, afirma: "Carece de fuerza cómica, de propiedad y corrección en el estilo; y mezclados los defectos de nuestras antiguas comedias con la regularidad violenia a que su autor quiso reducirla, resultó una imitación de carácter ambiguo y poco a propósito para sostenerse en el teatro, si alguna vez se huhiera intentado representarla" "2. Así pues, según el juicio de su propio hijo, se trata de una comedia sujeta al rigor del arte, que mezcla los defectos de nuestras antiguas comedias con la regularidad violenta, lo que significa que Leandro Moratín ha visto con claridad que la obra de su piadre es un híbrido de comedia barroca y comedia a la lrancesa. Es lo que quiero poner de relieve a continuación.

En La pesimetra hay cuatro elementos que revelan su situación estilística: la intriga de cuatro personajes, la

2. B.4.E., 2, pág. 316 . 
aceptación de las tres unidades, el uso de las relaciones y la polimetria.

A) La intriga de cuatro personajes. Las comedias de capa y espada preferían una intriga de cuatro personajes, dos femeninos y dos masculinos:

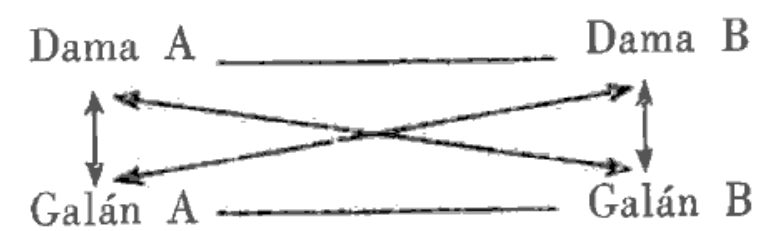

Por lo general, el galán $A$, que va a acabar unido a la dama $A$, intenta la conquista de la dama $B$, y lo contrario le ocurre al galán $B$, aunque en otros casos la iniciativa parte de las damas. Las peripecias que este esquema provoca pueden ser múltiples; las oblicuas ( $A$ hacia $B$ ), que son las que constituyen la parte central de la fábula de la comedia, pueden ser voluntarias o derivadas de errores o equívocos; puede haber una o dos (sólo una dama o un galán A hacia el galán o la dama B, o los dos galanes hacia las dos damas); puede incluso intervenir una quinta persona. En la comedia francesa, aunque no exenta de intrigas de cuatro personajes, lo frecuente es, sin embargo, la de tres, en la cual la acción se centra en una dama a la que quieren conquistar dos galanes. Es también el tipo de intriga que predomina en el teatro anterior a Lope de Vega, y el más frecuente en la comedia histórica del XVII y en los dramas de honor. En La petimetra la intriga es de cuatro personajes: Damián y Félix pretenden alternativamente a doña Jerónima y doña María, hasta que al final don Félix se casará con doña María y don Damián no tendrá más remedio que aceptar a la petimetra.

B) Las unidades. Una comedia escrita con el rigor del arte ha de estar necesariamente ajustada a las tres unidades de acción, lugar y tiempo. Esta ha sido también la intención de Nicolás Fernández de Moratín. La única acción de la comedia se desarrolla toda ella en el cuarto de doña Jerónima y en el térnino de un día. Ahora bien, Leandro Moratín habla de "la regularidad violenta" a que su padre sometió su comedia, y es cierto que las inverosimilitudes, 
a causa de ello, se multiplican: los dos personajes masculinos cuentan en el cuarto de las damas lo que nadie se atrevería a decir en lugar donde pudiera ser oído; en el breve tiempo de un día suceden tantas cosas, que don Félix, re. cién llegado a Madrid y que no conoce ni a doña Jerónima ni a doña María, piensa en casarse con la una y con la otra, y se casa finalmente con la segunda. De joven atolondrado se le podría calificar.

C) La relación. En la primera escena de Hombre pobre todo es trazas, de Calderón de la Barca, dice uno de los personajes:

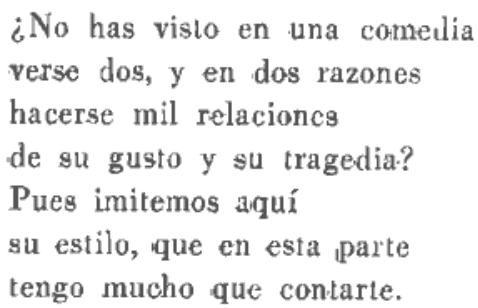

Se trata, efectivamente, de un rasgo característico de nuestro teatro barroco, utilizado fundamentalmente para exponer los antecedentes que no es posible ofrecer en acción y para incluir descripciones. Son naturalmente elementos no dramáticos, mientras que lo predominante en la comedia clásica francesa, aunque en ella no faltan las relaciones, es la utilización del diálogo dramático para dar los antecedentes, es decir, son los mismos personajes los que con su diálogo enteran a los espectadores de los datos fundamentales, al mismo tiempo que se caracterizan a sí mismos $o$, con sus comentarios, caracterizan a los otros personajes.

En el acto primero de La petimetra abundan precisamente las relaciones narrativas y descriptivas, aunque también hay escenas que tienen la función de presentar caracteres por medio del diálogo. De la primera relación que hace don Damián va a comentar don Félix en la penúltima escena de la comedia:

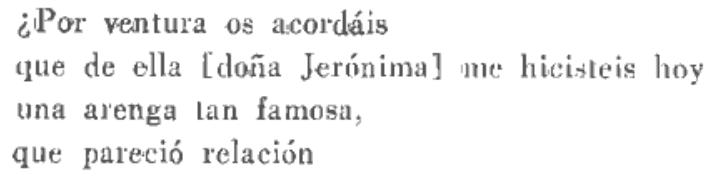


de don Pedro Calderón,

alabándola de hermosa? ${ }^{3}$,

lo que en definitiva demuestra una imitación consciente de Calderón de la Barca.

D) La métrica. Las comedias francesas preferían la prosa, frente a las españolas que usaban exclusivamente el verso. La petimetra está también en verso y, lo que es más importante, no se utiliza un solo tipo de estrofa, sino que Moratín pasa de las redondillas al romance y del romance a las redondillas. En nuestra comedia barroca predominaba el verso corto; en Moratín es el octosílabo el único que se utiliza. Pero hay que subrayar que frente a lo que era habilual en la comedia anterior, nuestro autor no usa más que dos estrofas y un solo metro.

Leandro Fernández de Moratín había observado claramente que la "regularidad violenta" no encajaba en un planteamiento dramático al antiguo estilo, y esto sin duda es lo que causa la poca consistencia de la obra. Pero es al mismo tiempo algo que trasciende la intención misma de Moratín. Quiero decir que Nicolás Moratín, al escribir su comedia, y aparte de que hubiera acertado o no, no pretendía escribir una comedia a la francesa sin más, según el modelo de un Molière, por ejemplo. El uso del verso y de la polimetría, la intriga de cuatro personajes, las relaciones calderonianas, la gran cantidad de acción dramática, el dinamismo de esta acción, las escenas con 5,6 y 7 personajes, cosas todas ellas poco o nada francesas, pero muy dentro de nuestro teatro barroco, no son una concesión a la fuerza, sino una característica del momento.

Moratín lo que hace es suavizar esos elementos. No se servirá más que de dos estrofas; apenas recurrirá al equivoco, con lo que las partes oblicuas de la intriga (A hacia B) son perfectamente conocidas de los espectadores, a los que nunca se intenta confundir; aunque la acción es movida, no llega al dinamismo de las comedias barrocas; hasta incluso se saca de escena a los personajes para episodios que un autor barroco hubiera presentado en ac-

3. B.A.E., 2, pág. 84 a. 
ción; si hay escenas con muchos personajes, las que más abundan son las de uno, dos o tres, que llegan a 39 , esto es, al $76 \%$ del total; el gracioso ha desaparecido, aunque queda una vaga sombra de él en Roque.

A estos elementos barrocos suavizados se añaden otros de importación francesa, como el estricto respeto de las unidades. Con todo ello resulta La petimetra una obra barroca moderada, en la que entran elementos característicos del barroquismo francés, más cercano que el español al ideal clásico. Y esta mezcla es lo que caracteriza al Rococó literario, al igual que en los retablos rococós desaparece el dinamismo y el amontonamiento de superficies y líneas curvas, en un intento de conseguir una perspectiva plana, dentro de la cual entran todavía en mayor o menor cantidad elementos típicamente barrocos, a los que no se les puede llamar ornamentales, puesto que tienen una clara función estructural dentro del conjunto.

\section{La tragedia, género Rococó}

Cuando se habla de la tragedia española de la segunda mitad del siglo XVIII, el calificativo que siempre se aplica es el de neoclásica; incluso se la suele considerar como el género neoclásico por excelencia. Sin embargo, se trata más bien de un género lípico del Rococó literario, que va después a teñirse de matices prerrománticos, que va a evolucionar muy poco durante el Neoclasieismo de los primeros años del siglo XIX y que incluso perdurará aún después de haber triunfado el drama histórico del Romanticismo.

En nuestro teatro del siglo XVI había habido una serie de intentos de adaptación de la tragedia clásica; perc casi todos buscaban al mismo tiempo nuevos caminos, creyendo que el género no podía ser directamente imitado para un público español. La Numancia de Cervantes acaso sea el intento más logrado de entonces. La opinión de su 
autor sobre el género fue ampliamente expuesta en el capítulo 48 de la primera parte del Quijote. De éste y de otros textos de los mismos años se deduce que de una $u$ otra forma todos pretenden transformar un género eminentemente culto en un género apto para el público heterogéneo que asistía a los teatros españoles. Y el que acertó fue el que acabó encontrando la fórmula de la comedia de historia, tan denigrada por los franceses de los siglos XVII y XVIII, pero cuyo acierto no es hoy posible poner en duda. De esta forma, mientras la tragedia francesa se hacía género de minorías cultas, la comedia histórica española era oída y aplaudida por cultos e ignorantes.

Cuando al llegar el siglo XVIII los círculos intelectuales vuelven a pensar en el noble género trágico, tampoco pueden evitar el plantearse el mismo problema que sus antecesores del XVI, aunque, como la historia nunca se repite, ahora tienen el modelo de las tragedias francesas e italianas, lo que modifica los datos del problema. De todas formas, hay un punto en el que todos prácticamente estarán de acuerdo y que será programáticamente expuesto por Jovellanos: el tema de la tragedia deberá ser buscado en la historia nacional. He aquí un lazo importante que une la tragedia rococó y neoclásica con la comedia histó. rica del barroco por un lado y con la comedia histórica del Romanticismo por el otro. Mucho antes de que en 1806 Mme. de Staël defendiera en su libro Sobre Alemania el drama histórico, libre de la traba de las reglas, ya Jovellanos había dicho, comentando su Pelayo:

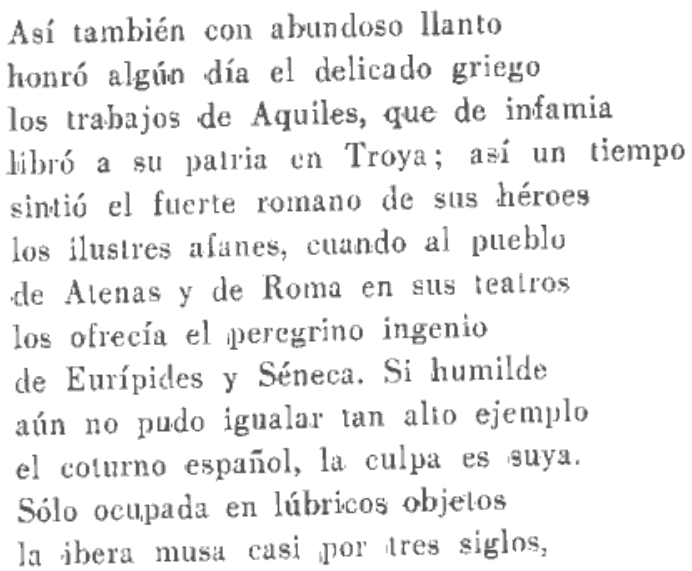




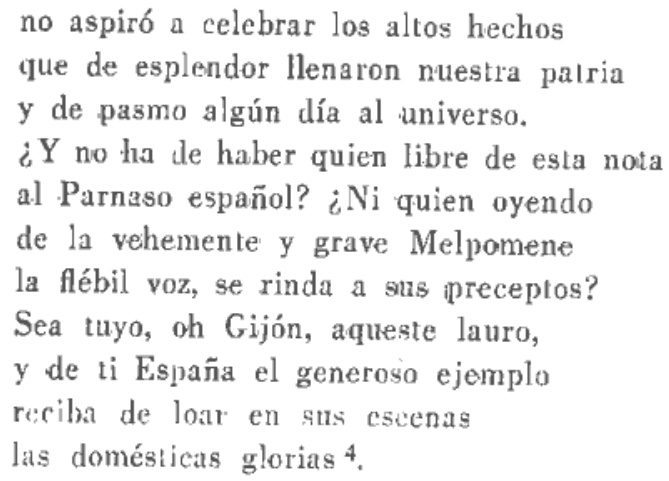

Este pensamiento de Jovellanos no era exclusivo suyo, sino que la idea de una tragedia de tema nacional estaba en el ambiente, y por eso al mismo tiempo que él escribe su Pelayo compone Nicolás Fernández de Moratín la Hormesinda, estrenada con grandes esfuerzos y tremenda oposición de los mismos comedianles, en 1770. Esla tragedia de Moratin es un ejemplo lípico de Iragedia rococó, aunque su valor literario sea escaso. Las díficultades para llevarla at las tablas del escenario se derivan del estilo francés en que estaba escrita, el cual se advierte en la falıa del gracioso, en haber dividido la obra en cinco actos, en utilizar un mismo tipo de verso a lo largo de todos ellos y en sustituir los momentos más movidos de la acción por una simple narración.

Pero se puede decir que aquí se acaba el estilo francés. Ya el arranque mismo de la obra plantea un problema lípico del leatro calderoniano: Munuza ha aspirado a la mano de Hormesinda, hermana de Pelayo, de ascendencia real; él es musulmán, bárbaro y villano, es decir, persona infamada; ella es noble, cristiana y española; sólo e) hecho de atreverse Munuza a proponer semejante pretensión es deshonroso. Todo el orgullo de la nobleza española está aquí expresado. Hormesinda no se rendirá: ante los ruegos del moro, ante sus amenazas, permanecerá inconmovible. Munuza pasa por ello del amor al aborrecimien. to, no diré que injustificadamente, pero sí con una rapidez

4. Gaspar Melchor de Jovellanos, Poesias, ed. de J. Caso González, Oviedo, I.D.E.A., 1961 [1962], págs. 201.202. 
inverosímil. Decide vengarse, y su venganza va a consistir en decir a Pelayo, que acaba de llegar de una embajada a Córdoba, que Hormesinda ha sido demasiado débil y se ha entregado a una persona innominada. Pelayo está afrentado por la deshonra de su hermana. Su concepto del honor es el típico del siglo XVII : al depender de la opinión ajena, al margen de la conducta individual, Pelayo no debe tener ni valor para mirarse, mientras no vengue su afrenta, y la venganza no puede ser otra que la muerte de la mujer que ha causado con su "libertinaje" tal deshonra; esta deshonra aumenta porque los otros la conocen, y el honor del hombre pende de la voluble fragilidad de las mujeres. De este modo puede Munuza hablar de la nobilísima ascendencia de Pelayo, de la fama, de la facilidad con que se pierde, de la infamia de un noble afrentado, de la hazaña que es el castigo del ofensor, de que para un noble godo es mejor ser heroico en la venganza que hermano afrentado. No hubiera dicho más en el teatro un noble del siglo XVII.

Este problema de honor, centro de la tragedia de Moratín, hubiera podido resolverse a bien poca costa; pero Moratín necesitaba prolongar la obra, y para ello recurre a un sistema perfectamente conocido en el teatro barroco: el de multiplicar los equívocos y los accidentes (muy poco franceses), con lo que Pelayo estará más de una vez a punto de sacrificar a su propia hermana y con lo que habrá que llegar a la mitad del acto $\mathrm{V}$ para que se dé cuenta del engaño de que ha sido víctima. Es decir, Moratín se sirve de recursos semejantes a los de la comedia de enredo.

Los resabios calderonianos pueden advertirse incluso en versos concretos, como cuando dice Hormesinda:

$$
\text { iAy, infeliz mujer! iAy, desdichada!, }
$$

que recuerda lo primero que dice Segismundo en La vida es sueño:

$$
\text { ¿Ay, mísero de mí! iAy, infelice! }
$$

La tragedia, es cierto, cumple con la regla de las unidades; pero la de tiempo sólo existe en cuanto que la trage- 
dia es intemporal, esto es, en cuanto que no se hace relerencia al liempo que pasa; la de lugar está lograda por el arti. ficio de no localizar las escenas: en el mismo lugar en que se reúnen Munuza y Tulga se entrevistan los nobles asturianos.

Pero si Hormesinda es un ejemplo típico de tragedia rococó, la tragedia característica del Rococó literario es La Raquel de García de la Huerta, estrenada en 1778. Es curioso observar que se trata de un tema legendario, sea cual sea su fundamento histórico, que recogen todas las Crónicas generales medievales, que vuelve de nuevo a interesar tras la publicación de la Historia de España del P. Mariana en 1601, y que en un cuarto de siglo reaparece en el canto XIX de la Jerusalén conquistada (1609) de Lope de Vega, en la comedia del aismo Lope Las paces de los reyes y judia de Toleto, anterior a 1617, y que, según Morley, es probablemente de 1610.1612, en La desgraciudn Raquel (1625) de Mira de Amescua, en el poema La Raquel de Luis de Ulloa y Pereyra, publicado en 1650 , pero acaso anterior a 1625 , aparte de $L a$ judia de Toledo de Diamante, anterior a 1667, que es un plagio de La desgraciada Ruguel, de Amescua, mús que una refundición. Esta lista demuestra que se Irata de un tema muy grato a los historiadores, poetas y dramaturgo.s de los 25 primeros años del siglo XVII. La elección del asunto por García de la Huerta enlaza, pues, con el gusto de siglo y medio antes.

Leandro Fernández de Moratín dice de La Raquel de Huerta: "Siguiendo el mismo plan de La judía de Toledo, de don Juan Bautista Diamante, no acertó a regularizarle sin añadirle graves defectos"s. No es cierto, desde luego, que Huerta siguiera el mismo plan de Diamante, ya que incluso se aparta bastante de él; pero además hay que añadir que tuvo muy en cuenta el poema de Ulloa.

Aunque Moratín no analiza esos graves delectos que dice haber añadido Huerta al plan de Diamante, creo que apunta a las relaciones que hay entre su tragedia y

5. B.A.E., 2, pág. 317 . 
las comedias barrocas, lo mismo que hemos visto en la crítica de La petimetra.

Efectivamente, al mismo tiempo que se respetan las unidades a toda costa y a pesar de alguna inverosimilitud, García de la Huerta puso en su tragedia mucha más acción de la que es pertinente en una tragedia clásica, redujo al mínimo posible las relaciones y las escenas sin movimiento, dio un carácter épico a algunas relaciones expositivas y utilizó en abundancia recursos melodramáticos. Algunos caracteres de su tragedia están bastante bien estudiados; pero en ellos casi todo es externo; apenas si se profundiza en el análisis, salvo en el caso de Raquel, que con su mezcla de soberbia, orgullo, amor verdadero, ambición, compromiso con su pueblo judío, miedo y ternura, era un gran carácler trágico. Lus demás, sin embargo, son cada uno prototipo de un determinado rasgo de carácter, sin que se llegue a ninguna complejidad psicológica. Incluso Huerta exagera ese rasgo: Hernán García será la franqueza y la generosidad, Alvar Fáñez la intransigencia, Garcerán Manrique la adulación, el rey Alfonso la insensatez política y la indecisión, Rubén la ambición del cerebro gris. Este último personaje, creación de Huerla, tiene mucha importancia estructural: una Raquel que decidiera por sí misma, llena de soberbia y ambición, víctima de los nobles castellanos tanto como de su amor y su orgullo, hubiera sido muy clásica, pero poco española. Huerta la coloca junto a Rubén, y es a éste al que hace responsable de sus más imprudentes decisiones, al que presenta con rasgos que le hacen odioso, el que será responsable de la muerte de Raquel, porque hasta el puñal asesino no va a manejarlo ningún noble castellano sino el vil judío, lo que a su vez permitirá al dramaturgo que Alfonso, con el mismo puñal (tópico frecuente), vengue en el asesino la sangre de su amada.

Con todo esto la Raquel tenía la apariencia de tragedia clásica, pero era en el fondo muy española y enlazaba muy visiblemente con nuestro teatro barroco. Por ello molestó a los que hacia 1780 estaban ya más acá del Rococó, pero agradó a los espectadores tanto que, según parece, su éxi- 
to fue pocas veces igualado en los leatros españoles del siglo XVIII.

\section{II \\ El teatro Prerromántico}

El Prerromanticismo uo es en realidad otra cosa que el pensamiento ilustrado trasvasado a forma artística, con la consiguiente implicación formal. De aquí que considerar lit literalura prerromántica sólo como un anuncio del futuro Romanticismo es errar el tiro y condenarse de antemano a no entenderla. Es cierlo que el problema ha estado en el nombre inventado por quienes no vieron la historia literaria de este período más que como transición hacia el Romanticismo, y que en consecuencia buscaban el origen de los rasgos típicamente románticos. Pero sucede que antes del Romanticismo ha habido una cultura, un pensamiento y una actitud humana ante los problemas políticos, sociales, religiosos, económicos y culturales, y esa cultura, ese pensamiento y esa actitud se diferencian perfectamente de los del período que hemos llamado ro. cocó y de los del período romántico, por muchos que sean los enlaces que haya entre los tres y sobre todo entre los dos últimos.

La literatura prerromántica no es la única que expresa arlísticamente el pensamiento ilustrado, ya que el Neocla. sicismo lambién puede estar ligado a la Ilustración. Sin embargo, en el Neoclasicismo puede o no darse pensamiento ilustrado, mientras que el Prerromanticismo es la consecuencia arlística directa de la Ilustración. Si de un lado podemos analizar sus rasgos estilísticos más relevantes y diferenciadores, de otro no podremos separarlo nunca de su estar al servicio de los ideales y actitudes ilustrados. Por eso es una literatura propia de un grupo de intelectuales, 
fundamentalmente culta, burguesa y comprometida en una acción política, social, económica, religiosa y cultural.

La literatura prerromántica en verso es abundante; también lo es, y aún más, la que se manifiesta en la prosa ensayística, la que aparece fundamentalmente en los periódicos como "discursos" o en los libros como "cartas". Sin embargo, en el género dramático es bastante más escasa. Hay una tragedia prerromántica, cuyo ejemplo más típico podría ser el Idomeneo de Cienfuegos; pero en general la tragedia tiene más tendencia a expresarse en forma neoclásica, aunque se cargue de ideas ilustradas, como el Pelayo de Quintana. Ahora bien, el género dramático prerromántico por excelencia es el drama urbano, más conocido como comedia lacrimosa, del cual en España el único ejemplo aceptable ha sido El delinciente honrado de Jovellanos.

\section{"El delincuente honrado» de Jovellanos}

Esta obra fue escrita en 1773 y estrenada al año siguiente con gran éxito de público, aunque creo que se trató más bien de un público culı y burgués. En ella, sobre la base de un hecho histórico ocurrido en 1758, Jovellanos pretende defender la tesis de que la ley concreta que condena igualmente, en el caso de un duelo, al retado y al retador, es una ley injusta; pero junto a esta tesis encontramos problemas más hondos y generales, porque lo que Jovellanos somete a crítica es sencillamente la manera de entender la justicia en general: condena él el viejo concepto de justicia y propugna un concepto ilustrado, que tiene relación con la importante revolución penal del siglo XVIII, representada fundamentalmente por el italiano Beccaria.

Toda la comedia es una exposición de nuevas ideas jurídicas y sociales, y no porque Jovellanos hubiera desarrollado una fábula que se prestara a ello, sino porque 
elige una que se pliega a la exposición de sus ideas, que es lo que de verdad le interesa. El Delincuente es un drama de tesis en el pleno sentido de esta expresión, y por ello todos sus elementos funcionales tienen valor en tanto que se relacionan con esas ideas centrales: nuevo concepto de la justicia, problema concreto de una ley sobre duelos.

Y en primer lugar podemos observarlo en los persona. jes: don Simón es el prototipo del viejo magistrado, don Justo del nuevo; Torcualo, el retado que ha aceptado el reto y es, ante la ley, responsable de una muerte en duelo, tendrá todas las cualidades del hombre virtúoso, precisamente para presentarle como víctima no sólo de una ley injusta, sino también de una siluación social condenable y que, por lo mismo, debe ser modificada por la educación y por la misma ley; Anselmo scrá el prototipo de la amistad, una amistad capaz de todo por el amigo, lo que no era otra cosa que uno de los grandes tópicos de la Ilustración, por otra parte plenamente vivido por Jovellanos, que por amistad hacia Cabarrús pone en peligro su carrera y es desterrado. La misma Laura, el personaje peor estudiado por Jovellanos, representa a la esposa amante, totalmente identificada con el marido al que ama, y en este sentido tuvo que ser en la época un personaje ejem. plar, cuando en la alta sociedad no eran hechos muy comunes la fidelidad conyugal y el amor de los esposos. En suma, de acuerdo con las doctrinas de Diderot, los personajes de Jovellanos no son caracteres, ni le interesan como tales, sino condiciones, es decir, caracteres presentados exclusivamente en función de su respectiva profesión o condición social.

Para llegar a las conclusiones que se propuso, JoveHlanos no utilizó en el Delincuente medios intelectuales, sino fundamentalniente sentimentales. La expresión comédies larmoyantes que se dio a estas obras fue en principio burlesca, por referencia a las escenas capaces de poner un mudo en la garganta del espectador. Estas escenas se encuentran también en el Delincuente, pero liene más imporlancia el conslante recurso al sentimiento. El dramaturgo 
nos descubre el alma sensible de los personajes, en vez de sus pasiones. El amor mismo está visto únicamente como sentimiento, y en el sentimiento se fundamenta el juego de la comedia, como el silencio de Torcuato después del duelo, la decisión de abandonar Segovia, el entregarse a la justicia o la voluntaria confesión de su delito. La obra entera reposa además sobre la sensibilidad: toda ella está llena de frases que hacen referencia directa o indirecta a las lágrimas.

La comedia está escrita en prosa, cosa totalmente necesaria al género de comedia urbana a que El delincuente hon rado pertenece. Es una prosa afectada, artificiosa, conscientemente rítmica, al menos en los parlamentos de Laura, Torcuato y don Justo. Pero merece la pena decir que en los años siguientes a su estreno la comedia fue puesta tres o cuatro veces en verso, hecho curioso que pone de relieve que la obra interesaba por sus tesis y por su sentimentalismo, y no por las innovaciones propiamente dramáticas adoptadas por su autor.

\section{III \\ El teatro Neoclásico}

Para definir el Neoclasicismo literario lo primero que necesitamos olvidar es la referencia al Barroco francés. No cabe duda de que nuestros neoclásicos, igual que los autores anteriores del Rococó o los prerrománticos, se lo conocían muy bien y lo tenían muy en cuenta; pero sólo en tanto que en él encontraban un modelo que se acercaba al ideal clásico, tal como éste empezó a verse entre el tercero y el último cuarto del siglo XVIII. Más importante es ver en artistas y literatos un deseo de pureża, de liberación de lo puramente contingente, de acercamiento a un ideal del hombre, de la vida y de las formas que tiene muy poco 
de platónico, en tanto que en la realidad visible no se ve una sombra de las ideas, sino la auténtica realidad, aunque manchada con imperfecciones; el arte entonces debe depurar esa realidad, para ofrecerla lo más cercana posible a un ideal intemporal e inexistente, pero que no está fuera de la humanidad que vive y sufre y se alegra y tiene problemas y comele errores.

En la comedia neoclásica tiene que manifestarse necesariamente ese conlaclo con la vida de cada día, y esto hace que prefiera los lemas que permiten la crítica social, cosa en la que coincide con la comedia del Rococó y del Prerromanticismo; pero frente a la primera será comedia de lesis y frente a la segunda preferirá manejar caracteres, por muy lípicos o universales que puedan ser.

\section{"El sí de las niñas» de Leandro Fernández de Moratín}

Renuncio en esla conferencia, por falta de tiempo, a tralar de la relación que existe entre la comedia neoclásica y la comedia rococó y directa o indirectamente con la comedia española de la segunda milad del siglo XVII, a pesar de que esa conexión nos sería tan útil como la que pueda haber con la comedia clásica francesa. Por otro lado voy a limitarme a una sola obra, El sí de las niñas, pero no sin advertir que, al contrario de lo que sucede con el teatro prerromántico, la comedia y la tragedia neoclásicas produce muchas y estimables obras a partir de los últimos años del siglo XVIII, y que en lo esencial perdurarán hasta más acá del Romanticismo.

En El sí de las niñas tenemos una comedia de tesis que se sirve de caracteres que pretenden ser prototípicos. Parte Moratín de un tema, el de la desigualdad del matrimonio entre viejo y jovencita (y no imporla que lo tome, junto con otra serie de detalles, de L'école des mères de Marivaux), que le preocupaba bastante, acaso en parle porque era su 
problema íntimo, al que con $E l$ sí de las niñas quiso dar una respuesta literaria anticipada, como quiere Lázaro Carreter ${ }^{6}$. De todas formas debemos ver en la obra el planteamiento de un tema que trasciende sus personales conflictos sentimentales. Por ello su actitud es crítica ya desde la primera escena, cuando don Diego expone su proyecto de boda al criado, y éste piensa que se trata de una boda igual entre los dos jóvenes Paquita y Carlos, con lo que el dramaturgo nos pone ante una situación ridícula, que se completará con otra serie de datos en las escenas siguientes. Pero los personajes no son condiciones, como en Jovellanos, sino caracteres con cierta pretensión de universalidad, cosa que distingue a la comedia de Moratín de las comedias lacrimosas y de las comedias del Rococó, al mismo tiempo que le acerea a la comedia clásica y en consecuencia en parte a la comedia barroca francesa.

Las relaciones han desaparecido totalmente de $E l$ sí de las niñas. Todos los antecedentes se dan dentro del diálogo propiamente dramático. La intriga se ha simplificado, quedando reducida a la conocida intriga triangular, con una mujer, Paquita, en el vértice, y dos hombres, don Diego y don Carlos, en relación con ella.

La simplificación alcanza también al número de personajes que dialogan, que es en el $84 \%$ de las 38 escenas de uno, dos o tres personajes; en los dos primeros actos sólo hay una escena en cada uno de cuatro personajes, en el tercero hay tres, aparte de la última escena, en que, como es lógico, se juntan todos los personajes fundamentales; pero incluso en esta escena hay que observar que faltan los dos criados, cuando enalquier comedia anterior hubiera terminado también con la boda de Rita y Calamoeha, cosa que además se había insinuado en la escena octava del acto primero.

A esto hay que añadir que la comedia está escrila en una prosa nada afectada, que quiere ser natural y espontánea. Desde este punto de vista hay que subrayar la can-

6. Fernando Lázaro, Moratín en su teatro [Oviedo], Cuadernos de la Cátedra Feijoo n. ${ }^{\circ}$, 1961, págs. 31-33. 
tidad de puntos suspensivos en el diálogo, esto es, de frases cortadas, sintácticamente incompletas, aunque halría que distinguir entre la frase lógicamente incompleta y la intuitivamente incompleta; en cualquier caso en Moratín este rasgo está en relación con su deseo de una prosa na. lural.

El sí de las niñas, que estaba terminada a mediados de 1801 , pero que no se estrenó hasta 1805, vino después del teatro prerromántico francés y español. Por ello no faltan las escenas sentimentales, especialmente al final; como tampoco falta la argumentación sentimental, aunque mezcla. da con argumentos de orden más intelectual.

Como es lógico, las unidades se guardan con toda escrupolosidad. Moralín procura, y consigue, no apartarse de la verosimilitud, esto es, no recurre a "la regularidad violenta" que él criticaba en las obras de su padre.

Crílica social sin estridencias, caracteres idealizados o universalizados, desaparición de recursos como las relaciones, simplificación de la intriga y de la complicación escénica, toques sentimentales, unidades a ultranza, verosimilitud a toda costa, ausencia de episodios líricos o épicos, prosa natural y espontánea, o que lo parece, y por ello un suave costumbrismo, que nos pone en contacto con la clase burguesa; esto es lo que fundamentalmente nos ofrece esta comedia neoclásica, y lo que también vamos a encontrar, en mayor o menor grado en las comedias neoclá. sicas, llamadas a veces moratinianas, que siguen a $E l$ sí de las niñas.

\section{Conclusiones}

Del análisis que hemos realizado podemos deducir algunas conclusiones, aunque sólo sean provisionales, en tanto que las voy a fundar únicamente en las obras analiza. das. Estas conclusiones pueden dar paso y materia al coloquio. 
1. Los autores que nacen en torno a 1735 , y cuyas obras principales se escriben entre 1760 y 1770 , constituyen fundamentalmente el grupo rococó; los nacidos en torno a 1750 , cuyas obras más importantes aparecen entre 1770 y 1790, forman un grupo de transición, educado en el Rococó, pero que avanza al Prerromanticismo o que anuncia el Neoclasicismo; en los nacidos en torno a 1762 , cuyas obras son posteriores a 1790 , encontramos ya a los autores decididamente neoclásicos.

2. $\quad$ El Rococó dramático junta multitud de recursos típicos de las comedias barrocas con una regularidad que suaviza el dinamismo y la complicación de la comedia anterior.

3. ${ }^{n} \quad$ El Prerromanticismo es la faceta literaria de la Ilustración, y en este sentido en él encontramos los mismos ideales de reforma social, económica y cultural que son típicos de ese grupo. Pero el Prerromanticismo comporta a su vez una forma especifica, que en la literatura dramática es fundamentalmente la mal llamada comedia lacrimosa.

4. ${ }^{2}$ El Neoclasicismo, que viene al final de nuestro período, se acerca a las formas clásicas, a través en parte del Barroco francés. Se evita toda complicación en la trama, se busca la naturalidad y la verosimilitud costumbrista, y el leatro, a través de caracteres más o menos universalizados, se aplica a la crítica social. En el Neoclasicismo podemos encontrar las mismas ideas ilustradas del Prerromanticismo.

He intentado deslindar con la mayor claridad posible los tres conceptos de Rococó, Prerromanticismo y Neocla. sicismo. He tenido que ser necesariamente breve, y en con. secuencia sintético. Por lo tanto quedan muchas lagunas y muchos problemas pendientes; pero si he conseguido que ustedes adquieran conciencia del problema, me daré por satisfecho. 